\title{
Chromatin remodeling complex NURF regulates thymocyte maturation
}

\author{
Joseph W. Landry, ${ }^{1,5,6}$ Subhadra Banerjee, ${ }^{2}$ Barbara Taylor, ${ }^{2}$ Peter D. Aplan, ${ }^{3}$ Alfred Singer, ${ }^{4}$ \\ and Carl $\mathrm{Wu}^{1}$ \\ ${ }^{1}$ Laboratory of Biochemistry and Molecular Cell Biology, National Cancer Institute, National Institutes of Health, Bethesda,
Maryland 20892, USA; ${ }^{2}$ FACS Core Laboratory, National Cancer Institute, National Institutes of Health, Bethesda, Maryland
20892, USA; ${ }^{3}$ Genetics Branch, National Cancer Institute, National Institutes of Health, Bethesda, Maryland 20889, USA;
${ }^{4}$ Experimental Immunology Branch, National Cancer Institute, National Institutes of Health, Bethesda, Maryland 20892, USA
}

The maturation of $T$ cells requires signaling from both cytokine and T-cell receptors to gene targets in chromatin, but how chromatin architecture influences this process is largely unknown. Here we show that thymocyte maturation post-positive selection is dependent on the nucleosome remodeling factor (NURF). Depletion of Bptf (bromodomain PHD finger transcription factor), the largest NURF subunit, in conditional mouse mutants results in developmental arrest beyond the $\mathrm{CD}^{+} \mathrm{CD}^{\text {int }}$ stage without affecting cellular proliferation, cellular apoptosis, or coreceptor gene expression. In the Bptf mutant, specific subsets of genes important for thymocyte development show aberrant expression. We also observed defects in DNase I-hypersensitive chromatin structures at Egr1, a prototypical Bptf-dependent gene that is required for efficient thymocyte development. Moreover, chromatin binding of the sequence-specific factor Srf (serum response factor) to Egr1 regulatory sites is dependent on Bptf function. Physical interactions between NURF and Srf suggest a model in which Srf recruits NURF to facilitate transcription factor binding at Bptf-dependent genes. These findings provide evidence for causal connections between NURF, transcription factor occupancy, and gene regulation during thymocyte development.

[Keywords: NURF; SRF; AP-1; Bptf; chromatin remodeling; positive selection]

Supplemental material is available for this article.

Received October 28, 2010; revised version accepted December 29, 2010.

Epigenetic regulators of transcription include histonemodifying enzymes, ATP-dependent chromatin remodeling complexes, DNA methylation, and the incorporation of histone variants (Goldberg et al. 2007). ATP-dependent chromatin remodeling complexes are classified into four major subfamilies (SWI/SNF, ISWI, CHD, and INO80) and are distinguished by the presence of a common SWI2/SNF2related catalytic ATPase subunit (Clapier and Cairns 2009). These enzymes catalyze specific activities, including nucleosome sliding on a DNA template in cis, histone eviction, and the incorporation of variant histones, each with dramatically different effects on chromatin structure.

The founding member of ISWI remodeling complexes is the nucleosome remodeling factor (NURF) (Tsukiyama and $\mathrm{Wu}$ 1995). Mammalian NURF is composed of BPTF (bromodomain PHD finger transcription factor); SNF2L,

\footnotetext{
${ }^{5}$ Present address: Department of Human and Molecular Genetics, Virginia Commonwealth University School of Medicine, Building 37, Room 6068, Richmond, VA 23298, USA.

${ }^{6}$ Corresponding author.

E-MAIL jwlandry2@vcu.edu; FAX (301) 435-3697.

Article is online at http://www.genesdev.org/cgi/doi/10.1101/gad.2007311.

Freely available online through the Genes \& Development Open Access option.
}

the ATPase subunit; and pRBAP46/48 (Barak et al. 2003). While the biochemical functions of remodeling complexes like NURF have been studied extensively (Choudhary and Varga-Weisz 2007), their biological functions in mammals are just beginning to be elucidated (Ho and Crabtree 2010). The NURF remodeling complex is essential for specific stages of metazoan development, functioning in prominent signaling pathways to the nucleus, including heat shock, TGF $\beta /$ Smad, JAK/STAT, WNT/ $\beta$-catenin, RB, and nuclear hormone receptors (Xiao et al. 2001; Badenhorst et al. 2005; Andersen et al. 2006; Li et al. 2006; Goller et al. 2008; Kwon et al. 2008; Landry et al. 2008; Song et al. 2009). To gain a better understanding of the biological functions of the mammalian NURF complex, we depleted the Bptf subunit during mouse T-cell development-a well-studied model of cellular differentiation (Starr et al. 2003).

Peripheral $\mathrm{T}$ cells bearing functional antigen-specific receptors are essential components of the mammalian immune system. The selection for T cells expressing functional T-cell antigen receptors (TCRs) occurs in the thymus during positive selection (Starr et al. 2003). Positively selecting $\mathrm{CD}^{+} \mathrm{CD}^{+}$double-positive (DP) thymocytes receive survival signals from the TCR pathway and commit to becoming a CD4 or CD8 single-positive (SP) thymocyte 
by integrating signals from both TCR and cytokine receptors (Brugnera et al. 2000). After lineage commitment, SP thymocytes complete the maturation process and exit the thymus to populate the periphery as a functional, naïve T cell.

How signals from both TCRs and cytokine receptors regulate thymocyte maturation has been a topic of intensive study. More than 100 genes have been identified, including a number that have important functions in the maturation of thymocytes and are regulated by the TCR pathway (Huang et al. 2004; Mick et al. 2004). These genes include cell surface receptors $C D 5, C D 69, C c r 7, I 17 R a$, $C D 2, C D 6$, and $P D-1$, and transcription factors Egr1, Egr2, and $I d 2$. In addition, lineage-specific transcription factors like Tox, Gata3, Th-Pok, and Runx3 are essential for the specific development of either CD4 or CD8 lineages (Rothenberg and Taghon 2005). In addition to genetic regulatory elements, epigenetic factors are emerging as major regulators of these gene targets (Merkenschlager and Wilson 2008).

Chromatin remodeling complexes have essential roles in many aspects of mammalian development, including T-cell development. Mutations in the Brg1 ATPase or accessory BAF subunits of the SWI/SNF family of complexes result in proliferation defects at multiple stages and defects in CD4 and CD8 coreceptor expression (Chi et al. 2002, 2003; Gebuhr et al. 2003). Mutations in the Chd4 ATPase subunit of the NuRD remodeling complex results in defective $\beta$ selection, CD4 coreceptor expression, and reduced cellular proliferation (Williams et al. 2004). These studies clearly demonstrate that complexes that regulate chromatin structure are essential for the development of thymocytes. However, little is known of the effects of the ISWI class of chromatin remodeling enzymes, whose biochemical actions, unlike that of Brgl and related enzymes, are exclusively involved in repositioning nucleosomes without histone loss or exchange (Choudhary and Varga-Weisz 2007).

Here, we report that the differentiation of positively selected thymocytes into phenotypically and functionally mature $\mathrm{T}$ cells is strictly dependent on NURF. We show that NURF regulates the chromatin structure and expression of genes important for $\mathrm{T}$ cell development. Functions for NURF as a specific regulator of thymocyte maturation are distinct from those of the SWI/SNF and NuRD remodeling complexes, suggesting that ATPdependent remodeling complexes have specific and nonoverlapping roles during regulated development. Analysis of transcription factor binding at a specific gene also provides evidence for a causal relationship between NURF and transcription factor occupancy in vivo.

\section{Results}

\section{Bptf is required for thymocyte development}

To investigate NURF function during thymocyte development, we depleted Bptf using LCKproximal-Cre to excise the Bptf floxed allele (Fig. 1A; Supplemental Fig. 1A,B; Hennet et al. 1995; Landry et al. 2008). In this system, Bptf $f^{\text {Floxed }}$ deletion begins during the $\mathrm{CD} 4^{-} \mathrm{CD} 8^{-}$ double-negative (DN) stages and is complete by the $\mathrm{CD} 4^{+}$ $\mathrm{CD}^{+}$DP stage of thymocyte development (Fig. 1B). LCKproximal-Cre excision of Bptf floxed results in exon 1-3 and exon 1-4 splice events, producing an out-of-frame transcript (data not shown) as reported previously for Cre excision of the Bptf floxed allele (Landry et al. 2008). Bptf deletion was confirmed by the absence of Bptf protein in total thymocyte extracts (Fig. 1C). Analysis of thymocytes by flow cytometry showed reductions in TCR $\beta^{\text {high }}$ (Fig. 1D), $\mathrm{CD}^{+} \mathrm{CD}^{+} 5^{+}$, and NKT cell populations (Supplemental Fig. 1C) but no significant differences in TCR $\gamma \delta$ or B220 ${ }^{+}$populations (data not shown). We further observed dramatic reductions in both $\mathrm{CD}^{+}$and $\mathrm{CD}_{8}^{+} \mathrm{SP}$ thymocytes and peripheral $\mathrm{T}$ cells and slight defects at the $\mathrm{DN}$ to-DP transition during development, without a significant reduction in thymus cellularity in both adults and embryos (Fig. 1E; Supplemental Fig. 1D,E). Equivalent BrdU incorporation into thymocyte populations in vivo suggests that cellular proliferation is normal in the absence of Bptf (Supplemental Fig. 2A,B). Analysis of residual peripheral $\mathrm{T}$ cells in Bptf knockout $(\mathrm{KO})$ mice showed the genomic Bptf $f^{\text {Floxed }}$ allele to be intact, suggesting that these few mature cells have escaped gene deletion (Supplemental

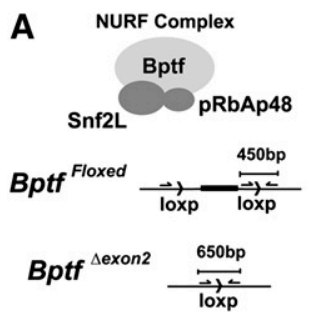

D

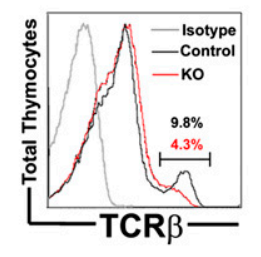

B
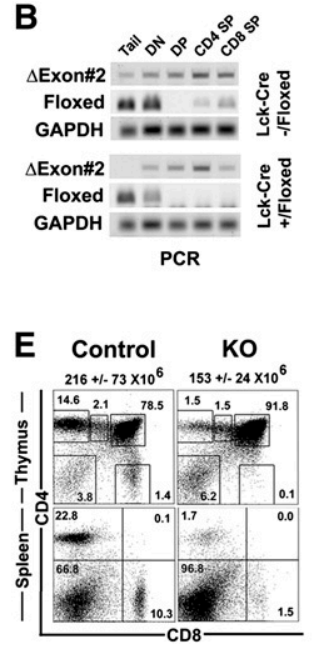

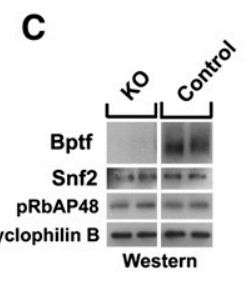

$\mathbf{F}$

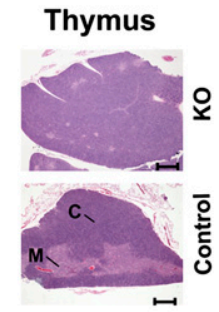

Figure 1. Bptf is required for thymocyte development. (A) Schematic of the NURF complex and the Bptf Floxed and $B p t f^{\Delta E x o n 2}$ alleles. Positions of PCR primers are shown. (B) PCR analysis on genomic DNA of electronically sorted thymocytes showing LCKproximal-Cre recombination efficiency. (C) Analysis of Bptf levels by Western blotting total thymocytes (two mice per group). (Control) Bptf ${ }^{+/ \text {Floxed }}$; (KO) LCKproximal-Cre, $B p t f^{-/ F l o x e d}$ throughout manuscript. (D) Flow cytometry analysis of total live thymocytes for TCR $\beta$ expression in Bptf $\mathrm{KO}$ and control animals. Numbers represent percent in gated population. (Gray) Isotype control; (black) control; (red) KO. (E) Flow cytometry analysis of CD4 and CD8 expression on thymocytes and spleenocytes to identify DN, DP, and SP populations. Values above the dot plot represent total cellularity of thymus. (F) H\&E-stained paraffin sections of $\mathrm{KO}$ and control thymus. (M) Medulla; (C) cortex. Bar, $500 \mu \mathrm{m}$. 
Fig. 2C). A histological examination showed the adult thymus lacks a medulla, a region populated by postselection $\mathrm{CD}^{+}$and $\mathrm{CD}^{+}$SP thymocytes (Fig. 1F). We observed normal rates of apoptosis by staining for annexin $\mathrm{V}^{+}$or TUNEL ${ }^{+}$cells in vivo, or by culturing DP thymocytes in medium or glucocorticoids or following anti-CD3E/ CD28 cross-linking (Supplemental Fig. 2D-H). From these results, we conclude that Bptf is essential for the development of mature thymocytes and peripheral $\mathrm{T}$ cells.

\section{Bptf is required for thymocyte maturation post-positive selection}

To further characterize the block in thymocyte differentiation, we fractionated thymocytes by expression of cell surface markers TCR $\beta$, HSA, CD69, and CD5 (Starr et al. 2003). We observed equivalent populations of selecting thymocytes with a $\mathrm{TCR}^{\text {int }} \mathrm{CD} 5^{\text {int }}, \mathrm{CD} 69^{\text {int }}$ phenotype, demonstrating that positive selection is quantitatively efficient. In contrast, Bptf deficiency results in an almost complete loss of mature thymocytes that appear phenotypically as TCR $\beta^{\text {high }} \mathrm{HSA}^{\text {low }}, \mathrm{CD} 69^{\text {negative }}$, and CD $5^{\text {high }}$ (Fig. 2A,B, red arrows). The few $\mathrm{CD}^{+} \mathrm{SP}$ thymocytes that remain are immature cells that are phenotypically CD69 ${ }^{\text {high }}, \mathrm{HSA}^{\text {high }}$, Ly6-D $\mathrm{D}^{\text {high }}$, Qa-2 $2^{\text {negative }}, \mathrm{H}-2 \mathrm{~K}^{\mathrm{b}}$ low , and Ccr $7^{\text {low }}$ (Fig. 2C; Starr et al. 2003). We expressed TCR transgenes (OT1, OT2, and HY) or the anti-apoptotic human BCL2 transgene in vivo in an attempt to rescue the maturation defect. These transgenes were unable to rescue the thymocyte maturation defects, suggesting that Bptf functions independently of apoptotic pathways and downstream from the TCR complex (Fig. 3A,B [red arrows], D; Supplemental Fig. 3A-C). Rescue of cells with the human $B C L 2$ transgene resulted only in $\mathrm{CD}^{+} \mathrm{SP}$ $\mathrm{CD} 69^{\text {high }}$, but no mature $\mathrm{CD}^{+} \mathrm{SP} \mathrm{CD} 9^{\text {negative }}$ thymocytes (Fig. 3E). In addition, we observed normal activation of T-cell and cytokine receptor signaling with Bptf deletion, further confirming that Bptf functions downstream from these pathways (Supplemental Fig. 3D-F).

These results demonstrate that Bptf is a new regulator of thymocyte maturation after positive selection. Because Bptf has been documented previously to be a coregulator of transcription (Barak et al. 2003), we propose that the defects are a consequence of deregulated transcription of genes important for thymocyte maturation.

\section{Bptf regulates gene targets of receptor-dependent thymocyte development}

To test this hypothesis, we monitored genome-wide transcription in equivalent cell populations of $\mathrm{KO}$ and control thymocytes by microarray analysis. In one approach, we stimulated electronically sorted, unsignaled CD69 ${ }^{\text {low }}$ DP thymocytes in culture with PMA + ionomycin $(\mathrm{P}+\mathrm{I})$ to mimic TCR signaling. In a second approach, we purified thymocytes from mice expressing TCR transgenes by magnetic separation to obtain immature (OT2: 95\% DP) and positively selected (OT1: $\sim 45 \% \mathrm{CD}^{+} \mathrm{CD}^{\text {int }}, \sim 45 \%$ DP) populations (Supplemental Fig. 4A,B). Bptf dependency was found for only 533 genes deregulated $\geq 1.5$-fold between $\mathrm{KO}$ and control (adjusted $P$-value $\leq 0.05$ ), with
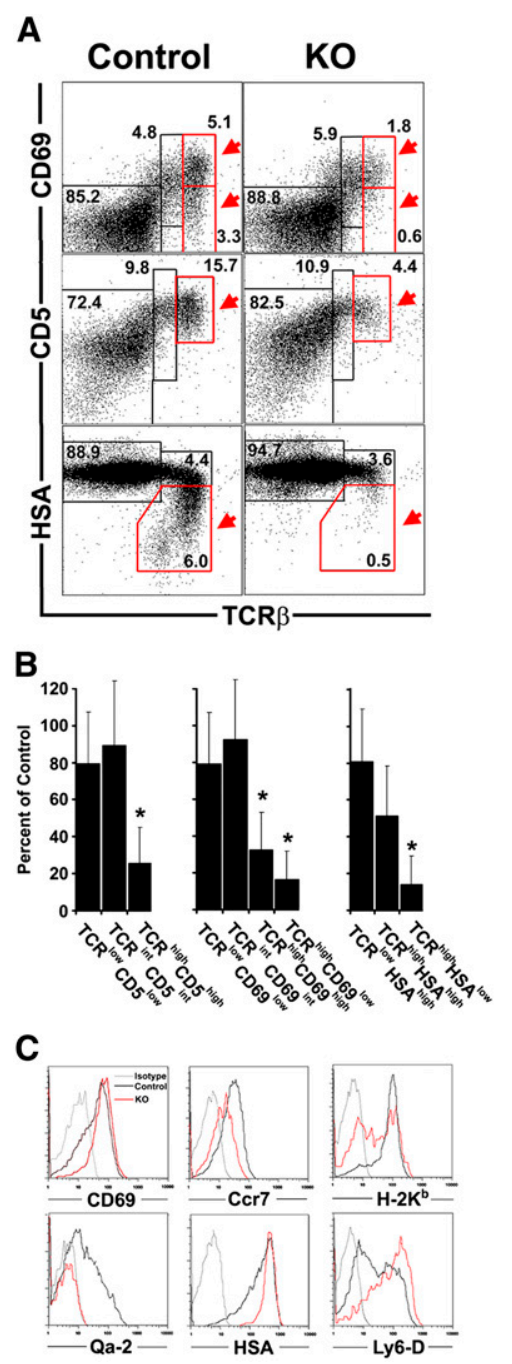

Figure 2. Bptf is required for thymocyte maturation. $(A)$ Flow cytometry analysis of TCR $\beta$ and CD5, CD69, or HSA on total live thymocytes. $(B)$ The bar graph represents total live thymocytes as a percent of control in each gate. $\left({ }^{\star}\right) P$-value $<0.01 ; N=$ 4. (C) Analysis of cell surface markers on $\mathrm{CD}^{+} \mathrm{SP}$ thymocytes by flow cytometry. (Gray) Isotype control; (black) control; (red) KO. Representative $N=5$.

152 genes showing lower expression and 154 genes showing higher expression than control (Supplemental Data Set S1). The remaining 224 genes have a more complex Bptf-dependent expression pattern, depending on cell type or culture condition (Fig. 4A). Of the 533 genes, we found 426 genes in the less mature DP and OT2 populations, demonstrating that a major fraction of affected genes requires Bptf prior to receptor-dependent thymocyte maturation. This implies that the effects of Bptf depletion on expression of these genes occurs well before the first observable block in thymocyte development. We also observed 107 of 533 genes exclusive to the OT1 or P+I-stimulated thymocytes, indicating that Bptf also regulates genes during receptor-dependent maturation. Gene ontology analysis of the data sets identified 

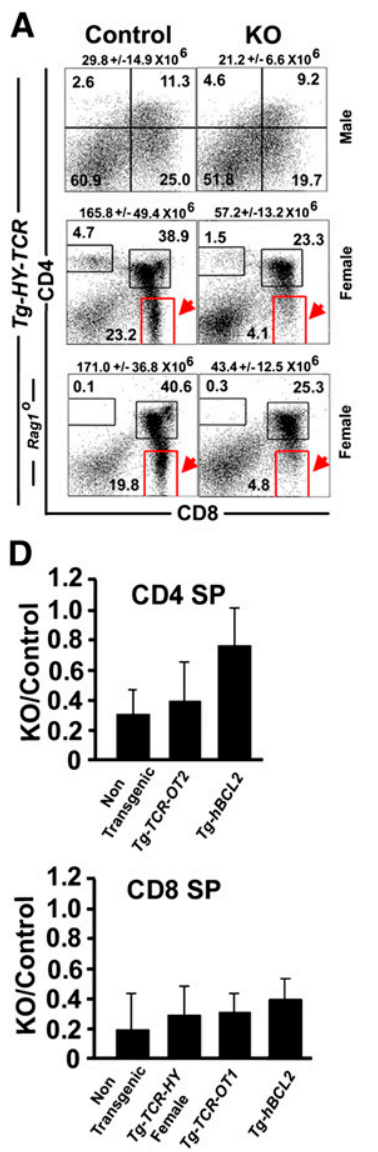

Figure 3. Bptf is required for positive selection. $(A)$ Total live Tg-HY-TCR (TCR V $\beta 8^{+}$population) thymocytes were analyzed in male and female mice by flow cytometry to identify DP and SP populations. Values above the dot plot represent total cellularity $(N=5)$. (B) Flow cytometry analysis of live Tg-OT1$T C R$ and $T g$-OT2-TCR thymocytes (TCR $\mathrm{V} 2^{+}$) to identify thymocyte populations. Values above the dot plot represent total cellularity of thymus $(N=5)$. $(C)$ Flow cytometry analysis of live Tg-hBCL2 thymocytes to identify DP and CD8 ${ }^{+}$and $\mathrm{CD}^{+}$SP populations. Values above the dot plot represent total cellularity of thymus $(N=5)$. $(D)$ Ratio of $\mathrm{KO}$ to control CD4 ${ }^{+}$ and $\mathrm{CD}^{+} \mathrm{SP}$ thymocytes on nontransgenic and transgenic backgrounds $(N=5)$. (E) Expression of CD69 on live CD4 ${ }^{+}$SP thymocytes from $\mathrm{Tg}$-OT2-TCR (TCR $\left.\mathrm{V} \alpha 2^{+}\right)$and $\mathrm{Tg}$ - $h B C L 2$ thymocytes. (Gray) Isotype control; (black) control; (red) KO. Representative $N=3$.

clusters annotated as "immune system" and related processes $(P$-value $<0.01)$ (Supplemental Fig. 5A).

Several laboratories have identified $>100$ genes during genome-wide investigations of transcriptional regulation during positive selection (Huang et al. 2004; Mick et al. 2004). Ten of these genes are found in our data sets (Ckap2L, Tpm4, Sqrdl, Mela, Id2, Il2, Socs3, Ly6D, Ets2, and CD531, and four of them show Bptf dependence during positive selection while six are Bptf-dependent even before positive selection (Fig. 4A,B; Supplemental Fig. 5B). To complement our microarray expression analysis, we also monitored the expression of eight well-characterized TCR-dependent genes (Egr1, Egr2, I12, Nur77, Ikaros, Rel B, JunB, and
$\left.B c l-X_{L}\right)$ in DP thymocytes before and after stimulation with P+I. We found two genes (Egr1 and RelB) that showed clearly increased expression in unstimulated Bptf KO cells compared with controls (Fig. 4C). Upon stimulation, seven out of eight genes, except for JunB, showed decreased expression for mutant cells, indicating that Bptf has a positive role in regulating these genes, which include Egr1 (Fig. 4D). We also observed consistent defects in the expression of TCR-regulated cell surface proteins Ccr7 and Il7R $\alpha$ in vivo during the transition from DP to $\mathrm{CD}^{+}$ $\mathrm{CD}^{\text {int }}$ thymocytes (Fig. 4E; Park et al. 2010). In contrast, we observed normal regulation of CD4 and CD8 coreceptors using an in vitro coreceptor reversal assay (Supplemental Fig. 6A; Brugnera et al. 2000). From these results, we conclude that Bptf regulates a restricted set of gene targets prior to and during receptor-dependent thymocyte maturation, including a number of genes regulated by the TCR pathway. Interestingly, the regulated transcription of Bptf-dependent genes such as Egr1, Egr2, Ikaros, Hes-1, $B c l-X_{L}$ and $I 17 r \alpha$ occurs at the earlier $\beta$-selection stage (Taghon et al. 2006). So, therefore, Bptf could also regulate the transcription of these genes many days before the observed block in thymocyte development (see below).

The phenotype of Bptf mutants exhibits an intriguing similarity to that of mutants for Themis, which has been speculated to be a component of the TCR signaling apparatus (Allen 2009). The similarity prompted us to investigate for overlap in gene expression data sets for Bptf and Themis mutants (Lesourne et al. 2009). We found normal Themis expression during Bptf KO thymocyte development, demonstrating that Bptf does not regulate Themis expression (Fig. 4B). Furthermore, a comparison of data sets reveals limited overlap in gene expression profiles (10 genes with a $P$-value of $\left.5.9 \times 10^{-6}\right)$, making connections between Themis and Bptf unclear at present (Supplemental Fig. 5C).

\section{Effects of Bptf on chromatin structure prior to positive selection}

The NURF complex is an ATP-dependent chromatin remodeling enzyme of the ISWI subfamily that repositions nucleosomes in vitro by histone octamer sliding without eviction (Tsukiyama and Wu 1995; Hamiche et al. 1999; Barak et al. 2003). Although ISWI enzymes have been reported to locally change nucleosome positioning at many hundreds of gene promoters to suppress antisense transcription in vivo (Fazzio and Tsukiyama 2003; Whitehouse et al. 2007), the physiological effects of ISWI-containing NURF on chromatin remains unclear in metazoans. As a first step toward addressing this question, we used quantitative chromatin profiling (Dorschner et al. 2004) to examine DNase I-hypertensive chromatin structures at Egr1, chosen as a representative Bptf-dependent gene that is also functionally important for thymocyte development (Bettini et al. 2002). DNase I-hypersensitive sites are generally considered to be a consequence of several related phenomena: transcription factor binding and changes in DNA conformation, changes in nucleosome positioning or occupancy, and disruption of higher-order 
A

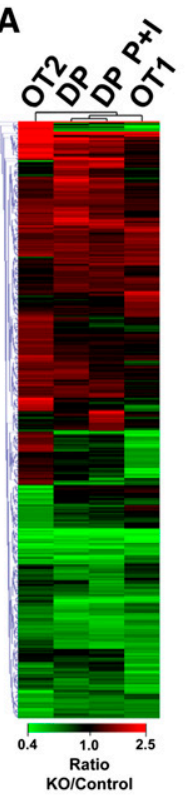

B

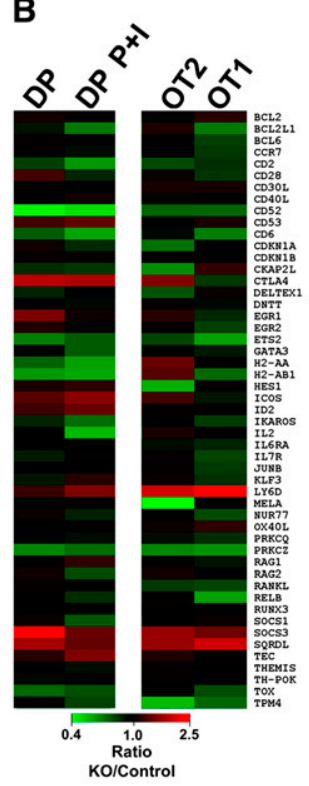

C

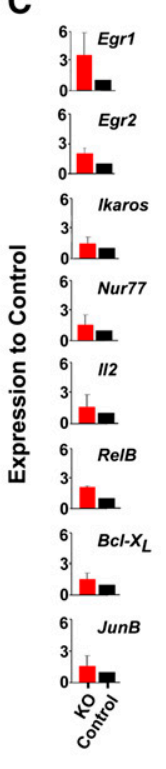

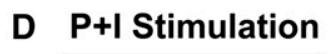
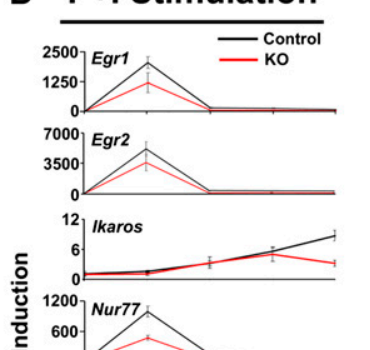

을

인 300

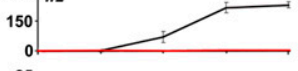

25] RelB

12.5 .

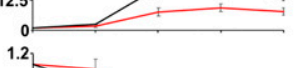

1.2
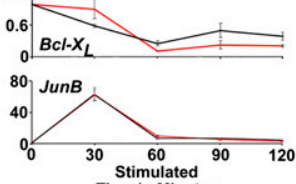

Time in Minutes

Figure 4. Bptf is required for regulated transcription during thymocyte development. (A) Microarray analysis of Bptf KO and control thymocytes followed by an hierarchical clustering of genes deregulated in unsignaled thymocytes (DP), stimulated thymocytes (DP $\mathrm{P}+\mathrm{I})$, OT2 transgeneexpressing thymocytes (OT2), and OT1 transgene-expressing thymocytes (OT1). (B) Microarray analysis of Bptf $\mathrm{KO}$ and control thymocytes followed by a manual clustering of genes regulated by positive selection. $(C)$ Gene expression analysis by qPCR of unstimulated panned DP thymocytes. $(D)$ Gene expression analysis by qPCR in panned DP thymocytes after stimulation with P+I. Representative $N=3$. $(E)$ Analysis of cell surface markers Ccr7 and Il7R $\alpha$ on DP and CD8 ${ }^{\text {int }} \mathrm{CD}^{+}$thymocytes by flow cytometry. (Gray) Isotype control; (black) control; (red) KO. Representative $N=5$.
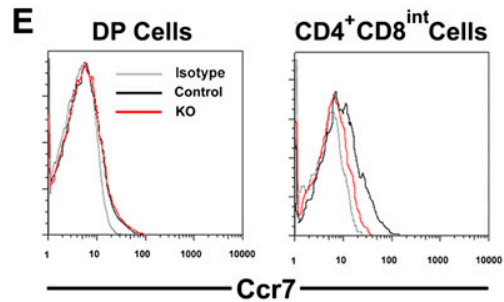
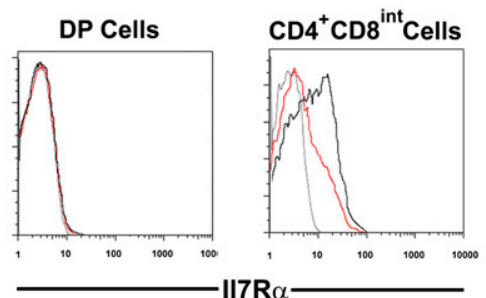

nucleosome packing (Gross and Garrard 1988). As shown in Figure 5A, we identified four DNase I-hypersensitive sites (black arrows, green highlights) over a 15 -kb region that showed clearly increased hypersensitivity (ratio, $<0.70$; $P$-value, $<0.01)$ when Bptf KO thymocytes at the DP stage $(\sim 95 \%$ DP) were compared with controls (Fig. 5A). Thus, Bptf is required for making DNase I sites less hypersensitive at a restricted number of sites across the Egr1 gene. To assess the earliest developmental period when Bptf-dependent chromatin remodeling occurs, we performed quantitative chromatin profiling on Bptf KO thymocytes from a $\mathrm{Rag}^{-/}$background ( 95\% DN3) (Supplemental Fig. 6B,C; Mombaerts et al. 1992). Many DNase I-hypersensitive sites were observed in control cells, but the same sites were also observed in Bptf KO $\mathrm{Rag}^{-1-} \mathrm{DN}$ thymocytes at the current level of resolution (Fig. 5A). These results indicate that Bptf is apparently not required for the establishment or maintenance of the DNase I-hypersensitive sites at Egr1 at or before the DN3 stage, but it is necessary for the closure of DNase I-hypersensitive sites as thymocytes develop from the DN3 to the DP stage.

As a second example of Bptf-dependent changes in DNase I hypersensitivity, we examined II2, which is not important for thymocyte maturation (Reya et al. 1998) but whose chromatin structure is known to undergo specific changes during the commitment to the thymocyte lineage (Siebenlist et al. 1986; Yui et al. 2001). In DP thymocytes, we observed three DNase I-hypersensitive sites in Bptf KO
DP thymocytes (Fig. 5B, black arrows, green highlights) that were absent in controls, indicating that Bptf is required to render these sites less hypersensitive at or before the DP stage (Fig. 5B). Two of these three sites $(-4.5 \mathrm{~kb}$ and $+6.6 \mathrm{~kb}$ ) were found to be hypersensitive in $\mathrm{Rag}^{-/-} \mathrm{DN}$ thymocytes for both control and Bptf KO, indicating that remodelers other than Bptf are responsible for the DNase I hypersensitivity (Fig. 5B, white arrows). However, one site $(+2.1 \mathrm{~kb})$ was observed to be hypersensitive in Bptf KO but not control thymocytes (Fig. 5B, black arrow, green highlight) at this stage of development (Fig. 5B), suggesting that Bptf can be required even before $\beta$ selection. Interestingly, these Bptf-dependent DNase I-hypersensitive sites were identified previously as being specific to the thymocyte lineage, including sites at $-4.5 \mathrm{~kb},-0.6 \mathrm{~kb}$, and $+2.5 \mathrm{~kb}$ (Siebenlist et al. 1986; Yui et al. 2001). Moreover, we observed Bptf-dependent changes of DNase I-hypersensitive sites at distal promoter-enhancer elements $(-300$ base pairs [bp] to $-700 \mathrm{bp}$ ) of $I 12$ in both DP and DN thymocytes (Supplemental Fig. 6D, black arrows); chromatin remodeling at these elements has been implicated in the transcriptional response to TCR signaling (Ward et al. 1998; Attema et al. 2002). We also examined the $C D 4$ silencer, a regulatory element that requires $\mathrm{Brg} 1$ to regulate its chromatin structure and function during thymocyte development, and found no Bptf-dependent effects on its chromatin structure (Supplemental Fig. 6E; Wan et al. 2009). Taken together, the results indicate that Bptf is a selective regulator of chromatin structure as early as the DN stages, 

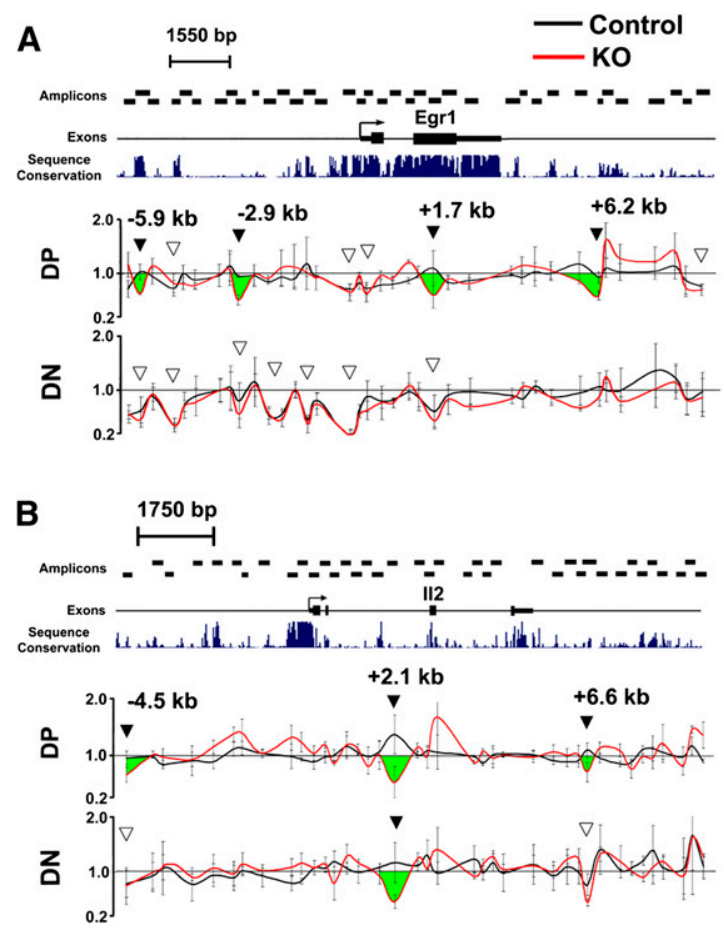

Figure 5. Bptf maintains chromatin structure during thymocyte development. DNase I hypersensitivity mapping by quantitative chromatin profiling at the Egr1 $(A)$ and $I 12(B)$ loci in Bptf $\mathrm{KO}$ and control panned DP and $\mathrm{Rag}^{-/-} \mathrm{DN}$ thymocytes. Bptfdependent (black arrows, green highlights) and Bptf-independent (open arrows) DNase I hypersensitivity sites were identified as decreased amplification of a PCR product from a DNase I-treated sample relative to an undigested control. Ratio, $<0.7$; $P$-value, $<0.01 ; N=3$.

prior to receptor-dependent thymocyte maturation for the two TCR-regulated genes examined.

\section{Bptf is required for DNA binding of transcription factors important for expression of Egr1}

Regulated transcription of Egr1 occurs as early as the $\beta$-selection stage of thymocyte development and continues during positive selection and thymocyte maturation through signaling pathways activated by the preTCR and TCR, respectively (Miyazaki 1997; Shao et al. 1997). Accordingly, we examined Egr1and Egr2 transcription in DN $\left(\mathrm{Rag1}^{-/-}\right)$cells and, like DP cells, found significant Bptf dependence for Egr1 and Egr2, but not JunB, transcription upon stimulation with $\mathrm{P}+\mathrm{I}$ (Fig. 6A). $\mathrm{P}+\mathrm{I}$ activates TCR signaling pathways in $\mathrm{Rag}^{-/} \mathrm{DN}$ thymocytes, mimicking the activation phase of $\beta$ selection. Given the early requirement of Bptf in establishing chromatin structure and regulated transcription in $\mathrm{Rag}^{-/-}$ DN cells, we examined the effects of NURF on transcription factor binding at these early stages to avoid complications due to indirect effects on later developmental stages (DP). We first determined whether the NURF complex is localized to Egr1 regulatory regions in DN thymocytes. Although chromatin immunoprecipitation (ChIP)-quality antibodies are not available for Bptf, we were able to observe the Snf2 subunit of the NURF complex at the upstream region and, albeit, at lower occupancy at the Egr1 promoter $(P$-value < 0.05) (Fig. 6B; Barak et al. 2003). Activation of Egr1 transcription has been shown to be regulated primarily by the ternary complex (SRF-TC) containing the serum response factor (Srf) and partners Elk-1 and Elk-4, and, to a minor extent, the transcription factors of the AP-1 and NFkB families (DeFranco et al. 1993; Aicher et al. 1999; Xi and Kersh 2003). Accordingly, we examined whether Bptf could interact with one or more of these factors. Toward this end, we performed coimmunoprecipitation experiments of endogenous proteins from native thymocyte extracts and found robust pull-down of Bptf with Srf and AP-1 / 10\% of input) and no detectable pull-down with $\mathrm{NFkB}$ and NFAT (Fig. 6C).

Previously, the NURF complex has been shown to remodel nucleosomes in an ATP-dependent manner to regulate the binding of transcription factors in vitro (Tsukiyama and Wu 1995; Kang et al. 2002). ChIP experiments have shown that Srf is constitutively bound to serum response elements (SREs) at the Egr1 promoter that are essential for the activation of Egr1 by TCR signaling (Xi and Kersh 2003; Tur et al. 2010). To determine whether Srf binding to Egr1 is dependent on Bptf, we performed ChIP on DN thymocytes and observed significant Bptf dependence for the occupancy of Srf at the promoter and the $-5.9 \mathrm{~kb}$ upstream region $(P$-value $<0.05)$ (Fig. 6D). A Western analysis shows equivalent levels of Srf protein expression in Bptf $\mathrm{KO}$ and control thymocytes, suggesting that defective chromatin binding is due to transcription factor access to the DNA and not to Srf expression (Supplemental Fig. 7A). Hence, Bptf-dependent binding of Srf at Egr1 provides a plausible mechanism for the observed defects in Egr1 transcription upon TCR signaling in Bptf mutants. Furthermore, the interactions between NURF and Srf are likely to be direct because of specific pull-down of a recombinant NURF complex with GST-Srf in vitro (Supplemental Fig. 7B). Taken together, these results suggest that the NURF complex is recruited to the Egr1 locus through interactions with Srf, and its recruitment is in turn important for Srf binding.

\section{Discussion}

Unique phenotypes for Bptf mutants during thymocyte development

In this study, we identified Bptf-and thereby the NURF complex in which it uniquely resides-as a novel regulator of thymocyte maturation after positive selection. Functions for Bptf as a regulator of post-selection thymocyte maturation are different from those documented for other chromatin remodeling complexes. Mutations in the Brg1 ATPase and BAF subunits of the SWI/SNF complexes and the Chd4 subunit of the NURD complex result in reduced cell survival, proliferation defects, and defective CD4 and/or CD8 coreceptor expression (Chi et al. 2002, 2003; Gebuhr et al. 2003; Williams et al. 2004). Distinct from these phenotypes, Bptf does not appear to 
A

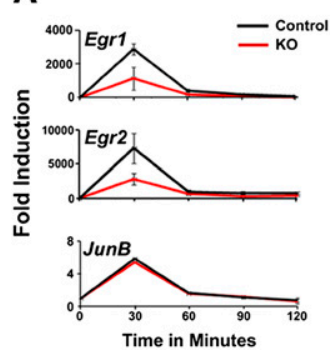

B
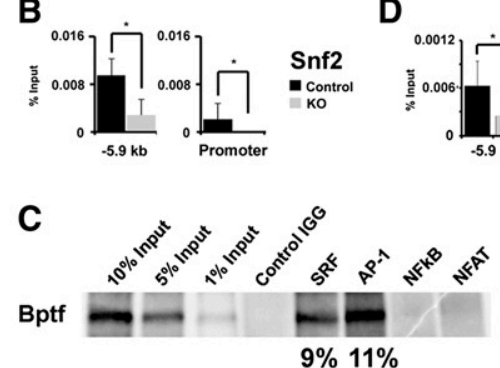

D

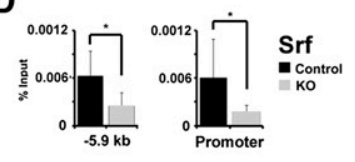

Figure 6. Physical and functional interactions between Bptf and Srf in thymocytes. (A) Gene expression analysis of Egr1, Egr2, and JunB by qPCR in $\mathrm{Rag}^{-/-} \mathrm{DN}$ thymocytes after stimulation with $\mathrm{P}+\mathrm{I}$. Representative $N=3$. (B) Snf2 ChIP in KO and control $\mathrm{Rag}^{-/-}$DN thymocytes at upstream $(-5.9$ $\mathrm{kb})$ and promoter regions of Egr1. $\left({ }^{\star}\right) P$-value < 0.05. $(C)$ Pull-down followed by quantitative Western blotting of Bptf by Srf and AP-1 from stimulated native thymocytes. $(D)$ Srf ChIP in $\mathrm{KO}$ and control $\mathrm{Rag}^{-/-} \mathrm{DN}$ thymocytes at upstream $(-5.9 \mathrm{~kb})$ and promoter regions of Egr1. $\left(^{\star}\right) P$-value $<0.05$.

regulate apoptosis, cellular proliferation, or the expression of the CD4/CD8 coreceptors, but rather Bptf specifically regulates thymocyte maturation after positive selection. We observe a Bptf requirement for the development of all mature thymocyte populations tested, including $\mathrm{TCR} \beta^{\text {high }}, \mathrm{NKT}$, and $\mathrm{CD} 4^{+} \mathrm{CD} 25^{+}$regulatory thymocytes. Functional TCR signaling is required for each of these thymocyte populations, strongly suggesting that Bptf regulates one or more steps of this pathway.

\section{Bptf is required for maturation of CD4/CD8 TCR $\beta^{+}$thymocytes}

We began a characterization of Bptf function in CD4/CD8 $\mathrm{TCR} \beta^{+}$thymocytes because they represent the predominant thymocyte lineage in the mouse and humans. Our initial results suggested that Bptf regulates one or more steps of thymocyte maturation. The use of three TCR transgenes (OT1, OT2, and HY) fails to complement the maturation defects in vivo, indicating that NURF functions downstream from the TCR complex. These results, in combination with results showing normal T-cell and cytokine receptor activation in Bptf mutants, suggest that the chromatin remodeling protein functions downstream from these pathways. A more detailed analysis of thymocyte development shows quantitatively efficient positive selection but severe defects in the development of the most mature TCR $\beta^{\text {high }} \mathrm{HSA}^{\text {low }}, \mathrm{CD} 69^{\text {low }}$, and $\mathrm{CD} 5^{\text {high }}$ thymocytes. These results document that Bptf is essential for thymocyte maturation after positive selection (Supplemental Fig. 8A). Identifying specific regulators of thymocyte maturation after positive selection is of great interest to developmental immunologists. To date, only Themis has been documented to specifically regulate thymocyte development at this period. Evidence suggests that Themis is a component of the plasma membrane-associated TCR signaling apparatus (Allen 2009). The minimal overlap between microarray data sets from Themis and Bptf mutant thymocytes suggests they may function in different pathways during thymocyte development.

To gain mechanistic insight into Bptf function, we used a microarray and quantitative RT-PCR (qRT-PCR) approach to comprehensively identify potential gene targets prior to and during positive selection. We identified many gene targets important for thymocyte development, in- cluding transcription factors (RelB, Ets2, Id2, Egr1, Egr2, Nur77, and Ikaros), adhesion and motility receptors (Ccr6, Ccr8, and Cxcr3), cytokine signaling components (II2 and Socs3), regulators of T-cell signaling $(C D 6, C D 52$, Icos, and Ctla4), and regulators of apoptosis (Bcl- $X_{L}$, Gadd $45 \beta$, $B c 12 A 1 B$, and Bcl2A1D). For example, Egr1 and Egr2 are known to have important functions regulating $\beta$ selection and positive selection (Bettini et al. 2002; Lawson et al. 2010). The Ets2 and Id2 transcription factors have been shown to regulate thymocyte development at $\beta$ selection (Engel and Murre 2001). Socs3 is important for $\beta$ selection and the activation of mature thymocytes (Croom et al. 2008). In addition, we observed decreased levels of cell surface expression of Ccr7 and Il7R $\alpha$ protein on $\mathrm{CD} 4^{+} \mathrm{CD} 8^{\text {int }}$ intermediates of positive selection. These markers are targets of TCR signaling and are essential for thymocyte development after positive selection, suggesting that their combined deregulation also contributes to the observed defects in thymocyte maturation (Ueno et al. 2004; Park et al. 2007, 2010). Hence, the cumulative effects of relatively small changes in transcription of multiple Bptf-dependent genes could well suffice to create a "synthetic" defect in thymocyte maturation.

\section{Bptf as a regulator of chromatin structure prior to positive selection}

The NURF complex in mammals and flies is a biochemically well-characterized ATP-dependent chromatin remodeling complex that has been shown to influence nucleosome positioning and nuclease hypersensitivity sites in vitro (Tsukiyama and Wu 1995; Hamiche et al. 1999; Barak et al. 2003). However, despite the genome-wide identification of DNase I-hypersensitive sites and nucleosome positioning correlating with cis-regulatory elements and transcription factor-binding sites (Gross and Garrard 1988; Rando and Chang 2009), causal relationships between chromatin remodeling and gene regulation remain poorly understood. We found that Egr1 and Il2 are two useful examples that show Bptf-dependent changes in chromatin structure and gene expression. Egr1 is a well-documented target of receptor-dependent thymocyte maturation that is important for thymocyte development; however, until this study, its chromatin structure had not been studied in thymocytes (Huang et al. 2004; Mick et al. 2004). In contrast to Egr1, Il2 is not 
required for receptor-dependent thymocyte development, but provides well-documented thymocyte-specific chromatin structures at its regulatory elements (Siebenlist et al. 1986; Chen and Rothenberg 1993; Yui et al. 2001). By quantitative chromatin profiling (Dorschner et al. 2004), we observed significant changes in DNase I hypersensitivity at Egr 1 and Il2 in DP thymocytes. These results suggest that Bptf, and thereby the NURF complex, has remodeling activities at these genes prior to the DP stage, most likely during the DN-to-DP transition (Supplemental Fig. 8A). At Il2, we observed Bptf to have essential roles in establishing previously documented thymocyte-specific DNase I sites at $-4.5 \mathrm{~kb},-0.6 \mathrm{~kb}$, and $+2.1 \mathrm{~kb}$ prior to or during the DN-to-DP transition (Siebenlist et al. 1986; Chen and Rothenberg 1993; Yui et al. 2001). Upstream regulatory elements (including the $-4.5 \mathrm{~kb}$ site) and the promoterenhancer $(-0.7 \mathrm{~kb}$ to $+0.1 \mathrm{~kb})$ have been shown previously to be important for $I 12$ regulation by TCR signals (Siebenlist et al. 1986; Chen and Rothenberg 1993; Yui et al. 2001). Like Il2, we observed Bptf-dependent changes in chromatin structure at Egr1; however, distal cis-regulatory elements have not been characterized. Because of the known correlation between DNase I-hypersensitive sites and regulatory elements, it will be of interest to use the four Bptf-dependent hypersensitive sites observed at Egr1 $(-5.9 \mathrm{~kb},-2.9 \mathrm{~kb},+3.6 \mathrm{~kb}$, and $+6.1 \mathrm{~kb})$ as a guide for the future identification of functional regulatory elements.

\section{Bptf as a regulator of Srf binding to chromatin}

The pre-TCR and the TCR and its coreceptors play an essential role in $\beta$ selection and positive selection, respectively (Starr et al. 2003). These receptors activate many transcription factors-including those of the AP-1, NFkB, NFAT, and Srf-to regulate gene targets (Wang et al. 2010). In many cases, the binding of these transcription factors to gene targets is essential for TCR-dependent regulation. Pull-downs of endogenous factors from native thymocytes reveals interactions between Bptf and Srf and AP-1 but not NFkB and NFAT. We further explored a functional connection between Bptf and Srf because mouse mutants of these factors have similar phenotypes. KOs of SRF-TC components Elk-4 and Srf have defects in positive selection, with a complete loss in mature thymocytes with Srf mutation (Costello et al. 2004, 2010; Fleige et al. 2007). Known Srf gene targets Egr1, Egr2, Nurr1, and Nurr77 were observed to be Bptf-dependent at one or more stages of thymocyte development, suggesting a functional connection at some gene targets. Consistent with this connection, we observe physical interactions between NURF and Srf in vitro, suggesting a direct interaction between the factors in vivo. More importantly, we found that Srf binding to Egr1, as revealed by ChIP, is dependent on Bptf. A similar requirement for SWI/SNF in the binding of RunX1 to the CD4 silencer in chromatin has been shown (Wan et al. 2009). It is possible that initial Srf binding to partially accessible SREs, the DNA-binding elements for Srf, recruits NURF to reposition nucleosomes, thereby allowing increased accessibility of SREs to additional Srf. The consequence of deficient Srf binding is likely decreased TCR-dependent activation of Egr1, as SREs have been shown to be essential for receptor-dependent activation (Xi and Kersh 2003). (The observed pull-down between NURF and AP-1 does not appear to reflect functional interactions at Egr1, as AP-1 binding to Egr1 chromatin is not reproducibly affected in Bptf KO DN thymocytes; however, ChIP shows AP-1 binding to Il2 chromatin is Bptf-dependent in thymocytes [JW Landry, unpubl.].) The decreased binding of Srf at the SREs of Egr1 does not appear to change DNase I accessibility at the promoter in DN cells. It is possible that the resolution of the DNase I assay is not sufficient, and that, at higher resolution, differences might be observed. Alternatively, NURF function at the Egr1 promoter may not be as a chromatin remodeling enzyme, but rather as a structural component assisting Srf binding.

Using Egr1 as a model Bptf-dependent gene, we propose that NURF repositions nucleosomes as early as the DNto-DP transition, when receptor-dependent transcription is first observed. The recruitment of NURF could be through physical interactions with the SRF-TC at the upstream and promoter regions of Egr1, as an example, and the altered nucleosome positioning could facilitate Srf binding (Supplemental Fig. 8B, panels i-ii). These two events, in turn, are likely required for the recruitment of other transcription factors and the general transcription machinery, leading to receptor-dependent activation of transcription (Supplemental Fig. 8B, panel ii). Given that SWI/SNF has been shown to possess novel activities distinct from classical remodeling, a similar role for NURF is not excluded (Jani et al. 2008). After $\beta$ selection, NURF plays an additional role in remodeling chromatin to eliminate DNase I-hypersensitive sites, perhaps directly as a chromatin remodeler, or indirectly through the regulation of transcription at $\beta$ selection. These changes in chromatin structure would also be important for the binding of transcription factors for gene reactivation in response to a second wave of TCR signaling during thymocyte maturation. Further investigation of NURF function at Egr1 during subsequent stages of receptor-dependent gene activation will allow us to define the precise repositioning of nucleosomes, binding of transcription factors, and underlying biochemical mechanisms necessary to achieve proper gene regulation in development.

\section{Materials and methods}

Animal husbandry

The Bptf ${ }^{\text {Floxed }}$ allele was developed in C.W.'s laboratory and now is available through The Jackson Laboratories as B6.129S1Bpt $f^{\mathrm{tmlCwu}} / \mathrm{J}$ (stock no. 009367). All other alleles were purchased from Jackson Laboratories or Taconic Farms. Animals were handled in compliance with guidelines established under the National Institutes of Health Animal Care and Use Committee under Animal Study Proposal LMCB001 and its modifications.

\section{Flow cytometry}

Thymocytes were stained with combinations of the antibodies as demanded by the experiment (see Supplemental Data Set S2 
for antibodies used in this study). Following staining, cells were washed and suspended in buffer with a viability dye. Data were collected using a LSRII flow cytometry machine (BD Biosciences) and were analyzed using Flow-Jo software.

\section{Coreceptor reversal assay}

Coreceptor reversal assays were performed as described previously (Brugnera et al. 2000).

\section{Chromatin structure assays}

DNase I nuclease accessibility analysis was performed on total $\mathrm{Rag}^{-/}$thymocytes or panned DP thymocytes. Following isolation, thymocytes were suspended in T-cell growth medium (RPMI, 10\% charcoal-stripped FCS, supplemented with glutamine, nonessential amino acids, $\beta$-mercaptoethanol, penicillin, streptomycin) and incubated for $2 \mathrm{~h}$ at $37^{\circ} \mathrm{C}$ and $5 \% \mathrm{CO}_{2}$ in a tissue culture incubator. Following resting, the cells were then fixed in $1 \%$ PFA in PBS for 15 min. Following fixation, nuclei were prepared and digested with $4.6 \mathrm{U} / \mathrm{mL}$ DNase I (Sigma) for $5 \mathrm{~min}$ at $37^{\circ} \mathrm{C}$ as described previously (Dorschner et al. 2004). DNA was then phenol-extracted, ethanol-precipitated, and analyzed by qPCR.

qPCR was performed using $2 \times$ DyNAmo Syprogreen qPCR kit (New England Biolabs) according to manufacturer's procedures. Briefly, reactions were composed of $5 \mu \mathrm{L}$ of $1.2 \mu \mathrm{M}$ forward and reverse primers, $5 \mu \mathrm{L}$ of DNA at $20 \mathrm{ng} / \mu \mathrm{L}$, and 10 $\mu \mathrm{L}$ of $2 \times$ qPCR mix. Reactions were heated for $3 \mathrm{~min}$ at $94^{\circ} \mathrm{C}$, then cycled for 40 cycles at $20 \mathrm{sec}$ at $94^{\circ} \mathrm{C}, 20 \mathrm{sec}$ at $60^{\circ} \mathrm{C}$, and 30 sec at $72^{\circ} \mathrm{C}$ prior to reading sample fluorescence. DNase I hypersensitivity was quantified relative to an amplicon at the Rhodopsin gene and an uncut DNA control as described previously (see Supplemental Data Set S2 for primer sequences) (Dorschner et al. 2004).

\section{Analysis of LCKproximal-Cre recombination}

Cell populations were sorted and DNA was extracted using standard techniques. DNA concentration was first normalized to GAPDH to ensure the linear amplification of the Bptf $f^{\text {Floxed }}$ or the Bptf delete exon 2 alleles (see Landry et al. 2008 for primer sequences). The deletion of exon 2 from LCKproximal-Cre, -/Floxed conditional KO mice was confirmed by sequencing the exon 1-8 junction in the Bptf transcripts as published previously (Landry et al. 2008).

For Western analysis, $50 \mu \mathrm{g}$ of total protein was separated by SDS-PAGE and transferred to PVDF using CAPS (Landry et al. 2008) or Tris-glycine transfer buffer at $20 \mathrm{~V}$ and 20-mA limits for $17 \mathrm{~h}$. Following transfer, blots were blocked in 5\% NFDM, $0.1 \%$ Tween 20, and PBS and probed with anti-Bptf/BPTF (Landry et al. 2008), Snf2 (Millipore, no. 05-698), anti-pRbAp48 (Santa Cruz Biotechnology, sc-33170), and anti-cyclophillin B (Abcam, ab3565-100).

\section{TCR and I17R stimulation}

For TCR stimulation assays, electronically sorted $\mathrm{CD} 4^{+}, \mathrm{CD} 8^{+}$ thymocytes were stimulated with anti-CD3 $\varepsilon$ and anti-CD28coupled magnetic beads as described previously. Cells and beads were mixed well and spun down at maximum speed in a microcentrifuge for $8 \mathrm{sec}$, then placed in a water bath for $5 \mathrm{sec}$ (p-p65, p-Elk1, and p-Ink analysis) or 15 min (Nfatlp dephosphorylation) at $37^{\circ} \mathrm{C}$. Following stimulation, proteins were extracted with Triazol (Sigma) according to the manufacturer's instructions. Extracted proteins were resolved by SDS-PAGE and analyzed by
Western blotting using antibodies to p-p65, p-Elk1, p-Jnk/Sapk (Cell Signaling Technologies, nos. 3039S, 4671S, and 9181S), and Nfatlp (Novus Biologicals, no. 300-504).

Il7R stimulation assays were performed on freshly isolated total thymocytes using a previously published protocol (Brugnera et al. 2000).

\section{Apoptosis assays}

Total thymocytes were isolated as described above. Cells $(5.0 \times$ $10^{6}$ ) were plated in six-well plates with $2 \mathrm{~mL}$ of T-cell growth medium containing untreated heat-inactivated FBS or charcoalstripped/heat-inactivated FBS. At 24 h, 48 h, and 72 h, cells were stained with antibodies, annexin $\mathrm{V}$, and viability dye and processed on a LSRII flow cytometer.

Negative selection was simulated in vitro using plate-bound antibody stimulation of the TCR. Ninety-six-well plates were coated with anti-CD3e-Biotin (clone 145-2C11) and anti-CD28Biotin (clone 37.51 ) overnight at a ratio of 1:5 over a concentration series. Total thymocytes were added to each well in T-cell growth medium and incubated overnight, then stained with antibodies, annexin V, and viability dye and processed on a LSRII flow cytometer.

Glucocorticoid-induced apoptosis was simulated by exposure to dexamethasone. Freshly isolated total thymocytes $\left(5.0 \times 10^{5}\right)$ were plated into 24 -well plates in $250-\mu \mathrm{L}$ volume of T-cell growth medium. Following the exposure to dexamethasone overnight, cells were stained with antibodies, annexin V, and viability dye and processed on a LSRII flow cytometer.

\section{ChIP}

Total thymocytes $\left(50 \times 10^{6}\right)$ were harvested from $\mathrm{Rag}^{-/-}$mice or panned DP thymocytes in T-cell growth medium and incubated for $2 \mathrm{~h}$ at $37^{\circ} \mathrm{C}$ and $5 \% \mathrm{CO}_{2}$. Cells were then washed with PBS and fixed in $2 \mathrm{mM}$ EGS (Pierce) in 25\% DMSO/75\% PBS for 30 min followed by $1 \%$ PFA in PBS for $30 \mathrm{~min}$ for Snf2 ChIP. For SRF ChIP, cells were fixed in $1 \%$ PFA in PBS for 15 min. Following fixation, cells were washed three times in PBS and processed using the ChIP procedure published by Upstate Biologicals. Antibodies used for pull-down were immunoprecipitation-grade Snf2 (Millipore, no. 05-698) and SRF (Santa Cruz Biotechnology, sc-335).

Quantification of pull-down was performed by real-time PCR using $2 \times$ DyNAmo Syprogreen qPCR kit (New England Biolabs) according to manufacturer's procedures. Briefly, reactions were composed of $5 \mu \mathrm{L}$ of $1.2 \mu \mathrm{M}$ forward and reverse primers, $5 \mu \mathrm{L}$ of diluted cDNA template, and $10 \mu \mathrm{L}$ of $2 \times$ qPCR mix (see Supplemental Table S2 for primer sequences). Reactions were heated for $10 \mathrm{~min}$ at $94^{\circ} \mathrm{C}$, then cycled for 40 cycles at $20 \mathrm{sec}$ at $94^{\circ} \mathrm{C}, 20 \mathrm{sec}$ at $60^{\circ} \mathrm{C}$, and $30 \mathrm{sec}$ at $72^{\circ} \mathrm{C}$. After each cycle, the sample was heated for $3 \mathrm{sec}$ to $78^{\circ} \mathrm{C}$ prior to reading sample fluorescence. Pull-downs were quantified as a percentage of input using a dilution series of input as a standard curve.

\section{Microarray and $q P C R$ analysis}

Microarray analysis was performed on purified or semipurified thymocyte populations. For in vitro stimulated data sets, electronic cell sorting was used to purify $\sim 30 \times 10^{6}$ cells as live $\mathrm{CD}^{+}, \mathrm{CD}^{+}, \mathrm{CD} 69^{\text {low }}$ from total thymocytes. Sorted cells were then collected and suspended in T-cell growth medium. Following purification, cells were allowed to recover in T-cell growth medium for $3 \mathrm{~h}$ at $37^{\circ} \mathrm{C}$ in a tissue culture incubator. Following recovery, half of the cells were stimulated with $10 \mathrm{ng} / \mathrm{mL}$ PMA and $250 \mathrm{ng} / \mathrm{mL}$ ionomycin for $1 \mathrm{~h}$. After stimulation, cells were 
collected and total RNA was extracted by Triazol (Sigma) according to the manufacturer's protocol.

OT1 TCR and OT2 TCR thymocytes were purified using MACS separation technology according to the manufacturer's procedures (Miltenyi Biotec). An anti-CD8 separation was used for purifying OT2 TCR thymocytes and an anti-CD4 separation was used for the purification of OT1 TCR thymocytes. Positively selected thymocytes were collected by $500 \mathrm{~g}$ centrifugation and total RNA was extracted by Triazol (Sigma) according to the manufacturer's protocol.

Total RNA fraction was further extracted with acid phenol, precipitated with ethanol, and resolved by electrophoresis to monitor integrity. RNA (100 ng) was labeled using the total RNA amplification kit (Ambion), hybridized to Whole-Mouse Genome Expression arrays version 2.0 (Illumina), and scanned using a Bead Station scanner (Illumina). Data sets were imported into Gene Spring for normalization and statistical analysis. Significantly deregulated genes in Mut/wild type were scored as having false-discovery rate (FDR) values of $<0.05$ and fold changes of expression at $>1.5$.

For qPCR analysis of TCR-responsive genes over a time course, panned DP thymocytes (95\% pure) or total thymocytes were harvested from $\mathrm{Rag}^{-1-}$ mice, purified, and suspended in T-cell growth medium. Following purification, cells were allowed to recover in T-cell growth medium for $2 \mathrm{~h}$ at $37^{\circ} \mathrm{C}$ in a tissue culture incubator. Following recovery, cells were stimulated with $10 \mathrm{ng} / \mathrm{mL}$ PMA and $250 \mathrm{ng} / \mathrm{mL}$ ionomycin, and samples were removed at designated time points (every $30 \mathrm{~min}$ ). After removal, cells were collected and total RNA was extracted by Triazol (Sigma) according to the manufacturer's protocol. RNA was reverse-transcribed using SuperScript II (Invitrogen) according to the manufacturer's protocol.

Quantification of gene expression was performed by real-time PCR using $2 \times$ DyNAmo Syprogreen qPCR kit (New England Biolabs) according to the manufacturer's procedures. Briefly, reactions were composed of $5 \mu \mathrm{L}$ of $1.2 \mu \mathrm{M}$ forward and reverse primers, $5 \mu \mathrm{L}$ of diluted cDNA template, and $10 \mu \mathrm{L}$ of $2 \times$ qPCR mix (see Supplemental Table S3 for primer sequences). Reactions were heated for $10 \mathrm{~min}$ at $94^{\circ} \mathrm{C}$, then cycled for 40 cycles at 20 sec at $94^{\circ} \mathrm{C}, 20 \mathrm{sec}$ at $60^{\circ} \mathrm{C}$, and $30 \mathrm{sec}$ at $72^{\circ} \mathrm{C}$. After each cycle, the sample was heated for $10 \mathrm{sec}$ to $78^{\circ} \mathrm{C}$ prior to reading sample fluorescence. Expression was quantified using the ddCT method using GAPDH as a control. Expression data are representative of three $\mathrm{KO}$ and control mice. Error bars are the standard deviation of four measurements for each time point.

\section{In vivo and in vitro pull-downs}

Total thymocytes $\left(500 \times 10^{6}\right)$ were harvested from C57BL6 mice and suspended in $10 \mathrm{~mL}$ of T-cell growth medium. Cells were induced overnight with $3 \mathrm{ng} / \mathrm{mL}$ PMA and $300 \mathrm{ng} / \mathrm{mL}$ ionomycin. Following induction, cells were centrifuged, resuspended in $1 \mathrm{~mL}$ of lysis buffer $(25 \mathrm{mM}$ HEPES at $\mathrm{pH} 7.6,100 \mathrm{mM} \mathrm{NaCl}$, $0.2 \% \mathrm{NP}-40,5 \mathrm{mM} \mathrm{MgCl} 2,10 \%$ glycerol, $2 \times$ protease inhibitor cocktail (Roche, no. 05056489001 ) and $1 \times$ phosphatase inhibitor cocktail (Sigma, P2850), and sonicated for $30 \mathrm{~min}$ in a Bioruptor sonicator. Following sonication, the lysate was centrifuged at $15,000 \mathrm{~g}$ for $15 \mathrm{~min}$ and the soluble fraction was removed. Pull-downs were performed on $150 \mu \mathrm{L}$ of lysate with $5 \mu \mathrm{g}$ of antibody coupled to protein G Dynabeads overnight at $4^{\circ} \mathrm{C}$ with rotation. The following day, beads were washed three times with lysis buffer with $0.5 \times$ protease inhibitors and eluted with $1 \%$ SDS at $65^{\circ} \mathrm{C}$. Eluted proteins were separated by $4 \%$ PAGE, blotted to PVDF, and Western blotted for Bptf using antibodies described previously (Landry et al. 2008). Antibodies used for pull-down were immunoprecipitation-grade RelA (Santa Cruz
Biotechnology, sc-109), c-Jun (Santa Cruz Biotechnology, sc-44), SRF (Santa Cruz Biotechnology, sc-335), NFATc1 (Santa Cruz Biotechnology, sc-13033), and control (Santa Cruz Biotechnology, sc-805). Quantitative Western blotting was performed with a Fujifilm LAS-3000 camera system.

GST fusions were made by subcloning SRF into pGEX4T-1 using standard cloning techniques. Approximately $5 \mu \mathrm{g}$ of resinbound fusion proteins were washed in in vitro binding buffer $(25$ $\mathrm{mM} \mathrm{HEPES}$ at $\mathrm{pH} 7.6,100 \mathrm{mM} \mathrm{NaCl}, 0.01 \% \mathrm{NP}-40,0.5 \mathrm{mM}$ $\mathrm{MgCl}_{2}, 10 \%$ glycerol), and Flag affinity-purified human NURF complex was added to each pull-down reaction. Samples were incubated for $1 \mathrm{~h}$ on ice and washed three times with binding buffer. Bound proteins were eluted from resin with protein loading buffer, resolved by SDS-PAGE, and transferred to PVDF. Flag-tagged BPTF from the NURF complex was detected by Western blotting with anti-Flag antibodies (Sigma, F1804) used to detect bound NURF complex. Quantitative Western blotting was performed with a Fujifilm LAS-3000 camera system.

\section{Acknowledgments}

We thank members of the Wu, Singer, and Aplan laboratories for critically reading the manuscript, discussions, and technical assistance. We thank Ron Schwartz, Remy Bousselut, Paul Love, and John Ashwell for helpful discussions. We thank John Stamatoyannopoulos and his laboratory for help with the quantitative chromatin profiling. We thank Paul Meltzer's laboratory for technical help with microarray experiments. We acknowledge the Frederick Histopathology Laboratory for providing sections of thymus tissue. This research was supported through fellowship \#PF-05-122-01-DDC from the American Cancer Society and travel awards from the National Cancer Institute and Mammalian Genome Society to J.L., and National Institutes of Health intramural research grants to A.S., P.A., and C.W. J.L. designed and performed experiments with input from P.A., A.S., and C.W. S.B. and B.T. performed electronic cell sorting. J.L. and C.W. wrote the manuscript and correspondence with contributions from P.A. and A.S.

\section{References}

Aicher WK, Sakamoto KM, Hack A, Eibel H. 1999. Analysis of functional elements in the human Egr-1 gene promoter. Rheumatol Int 18: 207-214.

Allen PM. 2009. Themis imposes new law and order on positive selection. Nat Immunol 10: 805-806.

Andersen EC, Lu X, Horvitz HR. 2006. C. elegans ISWI and NURF301 antagonize an Rb-like pathway in the determination of multiple cell fates. Development 133: 2695-2704.

Attema JL, Reeves R, Murray V, Levichkin I, Temple MD, Tremethick DJ, Shannon MF. 2002. The human IL-2 gene promoter can assemble a positioned nucleosome that becomes remodeled upon $\mathrm{T}$ cell activation. I Immunol 169: 2466-2476.

Badenhorst P, Xiao H, Cherbas L, Kwon SY, Voas M, Rebay I, Cherbas P, Wu C. 2005. The Drosophila nucleosome remodeling factor NURF is required for Ecdysteroid signaling and metamorphosis. Genes Dev 19: 2540-2545.

Barak O, Lazzaro MA, Lane WS, Speicher DW, Picketts DJ, Shiekhattar R. 2003. Isolation of human NURF: A regulator of Engrailed gene expression. EMBO J 22: 6089-6100.

Bettini M, Xi H, Milbrandt J, Kersh GJ. 2002. Thymocyte development in early growth response gene 1-deficient mice. J Immunol 169: 1713-1720.

Brugnera E, Bhandoola A, Cibotti R, Yu Q, Guinter TI, Yamashita Y, Sharrow SO, Singer A. 2000. Coreceptor reversal in the 
thymus: Signaled $\mathrm{CD}^{+} 8^{+}$thymocytes initially terminate CD8 transcription even when differentiating into $\mathrm{CD}^{+}$ T cells. Immunity 13: 59-71.

Chen D, Rothenberg EV. 1993. Molecular basis for developmental changes in interleukin-2 gene inducibility. Mol Cell Biol 13: $228-237$.

Chi TH, Wan M, Zhao K, Taniuchi I, Chen L, Littman DR, Crabtree GR. 2002. Reciprocal regulation of CD4/CD8 expression by SWI/SNF-like BAF complexes. Nature 418: 195-199.

Chi TH, Wan M, Lee PP, Akashi K, Metzger D, Chambon P, Wilson CB, Crabtree GR. 2003. Sequential roles of Brg, the ATPase subunit of BAF chromatin remodeling complexes, in thymocyte development. Immunity 19: 169-182.

Choudhary P, Varga-Weisz P. 2007. ATP-dependent chromatin remodelling: Action and reaction. Subcell Biochem 41: 29-43.

Clapier CR, Cairns BR. 2009. The biology of chromatin remodeling complexes. Annu Rev Biochem 78: 273-304.

Costello PS, Nicolas RH, Watanabe Y, Rosewell I, Treisman R. 2004. Ternary complex factor SAP-1 is required for Erkmediated thymocyte positive selection. Nat Immunol 5: 289-298.

Costello P, Nicolas R, Willoughby J, Wasylyk B, Nordheim A, Treisman R. 2010. Ternary complex factors SAP-1 and Elk-1, but not net, are functionally equivalent in thymocyte development. J Immunol 185: 1082-1092.

Croom HA, Izon DJ, Chong MM, Curtis DJ, Roberts AW, Kay TW, Hilton DJ, Alexander WS, Starr R. 2008. Perturbed thymopoiesis in vitro in the absence of suppressor of cytokine signalling 1 and 3. Mol Immunol 45: 2888-2896.

DeFranco C, Damon DH, Endoh M, Wagner JA. 1993. Nerve growth factor induces transcription of NGFIA through complex regulatory elements that are also sensitive to serum and phorbol 12-myristate 13-acetate. Mol Endocrinol 7: 365-379.

Dorschner MO, Hawrylycz M, Humbert R, Wallace JC, Shafer A, Kawamoto J, Mack J, Hall R, Goldy J, Sabo PJ, et al. 2004. High-throughput localization of functional elements by quantitative chromatin profiling. Nat Methods 1: 219-225.

Engel I, Murre C. 2001. The function of E- and Id proteins in lymphocyte development. Nat Rev Immunol 1: 193-199.

Fazzio TG, Tsukiyama T. 2003. Chromatin remodeling in vivo: Evidence for a nucleosome sliding mechanism. Mol Cell 12: 1333-1340.

Fleige A, Alberti S, Grobe L, Frischmann U, Geffers R, Muller W, Nordheim A, Schippers A. 2007. Serum response factor contributes selectively to lymphocyte development. I Biol Chem 282: 24320-24328.

Gebuhr TC, Kovalev GI, Bultman S, Godfrey V, Su L, Magnuson T. 2003. The role of Brg1, a catalytic subunit of mammalian chromatin-remodeling complexes, in $\mathrm{T}$ cell development. I Exp Med 198: 1937-1949.

Goldberg AD, Allis CD, Bernstein E. 2007. Epigenetics: A landscape takes shape. Cell 128: 635-638.

Goller T, Vauti F, Ramasamy S, Arnold HH. 2008. Transcriptional regulator BPTF/FAC1 is essential for trophoblast differentiation during early mouse development. Mol Cell Biol 28: 6819-6827.

Gross DS, Garrard WT. 1988. Nuclease hypersensitive sites in chromatin. Annu Rev Biochem 57: 159-197.

Hamiche A, Sandaltzopoulos R, Gdula DA, Wu C. 1999. ATPdependent histone octamer sliding mediated by the chromatin remodeling complex NURF. Cell 97: 833-842.

Hennet T, Hagen FK, Tabak LA, Marth JD. 1995. T-cell-specific deletion of a polypeptide $\mathrm{N}$-acetylgalactosaminyl-transferase gene by site-directed recombination. Proc Natl Acad Sci 92: 12070-12074.
Ho L, Crabtree GR. 2010. Chromatin remodelling during development. Nature 463: 474-484.

Huang YH, Li D, Winoto A, Robey EA. 2004. Distinct transcriptional programs in thymocytes responding to $\mathrm{T}$ cell receptor, Notch, and positive selection signals. Proc Natl Acad Sci 101: 4936-4941.

Jani A, Wan M, Zhang J, Cui K, Wu J, Preston-Hurlburt P, Khatri $\mathrm{R}$, Zhao K, Chi T. 2008. A novel genetic strategy reveals unexpected roles of the Swi-Snf-like chromatin-remodeling BAF complex in thymocyte development. I Exp Med 205: 2813-2825.

Kang JG, Hamiche A, Wu C. 2002. GAL4 directs nucleosome sliding induced by NURF. EMBO J 21: 1406-1413.

Kwon SY, Xiao H, Glover BP, Tjian R, Wu C, Badenhorst P. 2008. The nucleosome remodeling factor (NURF) regulates genes involved in Drosophila innate immunity. Dev Biol 316: 538547.

Landry J, Sharov AA, Piao Y, Sharova LV, Xiao H, Southon E, Matta J, Tessarollo L, Zhang YE, Ko MS, et al. 2008. Essential role of chromatin remodeling protein Bptf in early mouse embryos and embryonic stem cells. PLoS Genet 4: e1000241. doi: 10.1371/journal.pgen.1000241.

Lawson VJ, Weston K, Maurice D. 2010. Early growth response 2 regulates the survival of thymocytes during positive selection. Eur I Immunol 40: 232-241.

Lesourne R, Uehara S, Lee J, Song KD, Li L, Pinkhasov J, Zhang Y, Weng NP, Wildt KF, Wang L, et al. 2009. Themis, a T cellspecific protein important for late thymocyte development. Nat Immunol 10: 840-847.

Li H, Ilin S, Wang W, Duncan EM, Wysocka J, Allis CD, Patel DJ. 2006. Molecular basis for site-specific read-out of histone H3K4me3 by the BPTF PHD finger of NURF. Nature 442: 91-95.

Merkenschlager M, Wilson CB. 2008. RNAi and chromatin in $\mathrm{T}$ cell development and function. Curr Opin Immunol 20: 131-138.

Mick VE, Starr TK, McCaughtry TM, McNeil LK, Hogquist KA. 2004. The regulated expression of a diverse set of genes during thymocyte positive selection in vivo. J Immunol 173: 5434-5444.

Miyazaki T. 1997. Two distinct steps during thymocyte maturation from $\mathrm{CD} 4{ }^{-} \mathrm{CD} 8{ }^{-}$to $\mathrm{CD} 4^{+} \mathrm{CD} 8^{+}$distinguished in the early growth response (Egr)-1 transgenic mice with a recombinase-activating gene-deficient background. J Exp Med 186: 877-885.

Mombaerts P, Iacomini J, Johnson RS, Herrup K, Tonegawa S, Papaioannou VE. 1992. RAG-1-deficient mice have no mature B and T lymphocytes. Cell 68: 869-877.

Park JH, Adoro S, Lucas PJ, Sarafova SD, Alag AS, Doan LL, Erman B, Liu X, Ellmeier W, Bosselut R, et al. 2007. 'Coreceptor tuning': Cytokine signals transcriptionally tailor CD8 coreceptor expression to the self-specificity of the TCR. Nat Immunol 8: 1049-1059.

Park JH, Adoro S, Guinter T, Erman B, Alag AS, Catalfamo M, Kimura MY, Cui Y, Lucas PJ, Gress RE, et al. 2010. Signaling by intrathymic cytokines, not $\mathrm{T}$ cell antigen receptors, specifies CD8 lineage choice and promotes the differentiation of cytotoxic-lineage $\mathrm{T}$ cells. Nat Immunol 11: 257-264.

Rando OJ, Chang HY. 2009. Genome-wide views of chromatin structure. Annu Rev Biochem 78: 245-271.

Reya T, Bassiri H, Biancaniello R, Carding SR. 1998. Thymic stromal-cell abnormalities and dysregulated T-cell development in IL-2-deficient mice. Dev Immunol 5: 287-302.

Rothenberg EV, Taghon T. 2005. Molecular genetics of T cell development. Annu Rev Immunol 23: 601-649. 
Shao H, Kono DH, Chen LY, Rubin EM, Kaye J. 1997. Induction of the early growth response (Egr) family of transcription factors during thymic selection. I Exp Med 185: 731-744.

Siebenlist U, Durand DB, Bressler P, Holbrook NJ, Norris CA, Kamoun M, Kant JA, Crabtree GR. 1986. Promoter region of interleukin-2 gene undergoes chromatin structure changes and confers inducibility on chloramphenicol acetyltransferase gene during activation of T cells. Mol Cell Biol 6: 30423049.

Song H, Spichiger-Haeusermann C, Basler K. 2009. The ISWIcontaining NURF complex regulates the output of the canonical Wingless pathway. EMBO Rep 10: 1140-1146.

Starr TK, Jameson SC, Hogquist KA. 2003. Positive and negative selection of T cells. Annu Rev Immunol 21: 139-176.

Taghon T, Yui MA, Pant R, Diamond RA, Rothenberg EV. 2006. Developmental and molecular characterization of emerging $\beta$ - and $\gamma \delta$-selected pre-T cells in the adult mouse thymus. Immunity 24: 53-64.

Tsukiyama T, Wu C. 1995. Purification and properties of an ATP-dependent nucleosome remodeling factor. Cell 83: 1011-1020.

Tur G, Georgieva EI, Gagete A, Lopez-Rodas G, Rodriguez JL, Franco L. 2010. Factor binding and chromatin modification in the promoter of murine Egr1 gene upon induction. Cell Mol Life Sci 67: 4065-4077.

Ueno T, Saito F, Gray DH, Kuse S, Hieshima K, Nakano H, Kakiuchi T, Lipp M, Boyd RL, Takahama Y. 2004. CCR7 signals are essential for cortex-medulla migration of developing thymocytes. J Exp Med 200: 493-505.

Wan M, Zhang J, Lai D, Jani A, Prestone-Hurlburt P, Zhao L, Ramachandran A, Schnitzler GR, Chi T. 2009. Molecular basis of CD4 repression by the Swi/Snf-like BAF chromatin remodeling complex. Eur J Immunol 39: 580-588.

Wang L, Xiong Y, Bosselut R. 2010. Tenuous paths in unexplored territory: From $\mathrm{T}$ cell receptor signaling to effector gene expression during thymocyte selection. Semin Immunol 22: 294-302.

Ward SB, Hernandez-Hoyos G, Chen F, Waterman M, Reeves R, Rothenberg EV. 1998. Chromatin remodeling of the interleukin-2 gene: Distinct alterations in the proximal versus distal enhancer regions. Nucleic Acids Res 26: 2923-2934.

Whitehouse I, Rando OJ, Delrow J, Tsukiyama T. 2007. Chromatin remodelling at promoters suppresses antisense transcription. Nature 450: 1031-1035.

Williams CJ, Naito T, Arco PG, Seavitt JR, Cashman SM, De Souza B, Qi X, Keables P, Von Andrian UH, Georgopoulos K. 2004. The chromatin remodeler Mi-2 $\beta$ is required for CD4 expression and $\mathrm{T}$ cell development. Immunity 20: 719-733.

Xi H, Kersh GJ. 2003. Induction of the early growth response gene 1 promoter by TCR agonists and partial agonists: Ligand potency is related to sustained phosphorylation of extracellular signal-related kinase substrates. I Immunol 170: 315-324.

Xiao H, Sandaltzopoulos R, Wang HM, Hamiche A, Ranallo R, Lee KM, Fu D, Wu C. 2001. Dual functions of largest NURF subunit NURF301 in nucleosome sliding and transcription factor interactions. Mol Cell 8: 531-543.

Yui MA, Hernandez-Hoyos G, Rothenberg EV. 2001. A new regulatory region of the IL-2 locus that confers positionindependent transgene expression. I Immunol 166: 17301739 . 


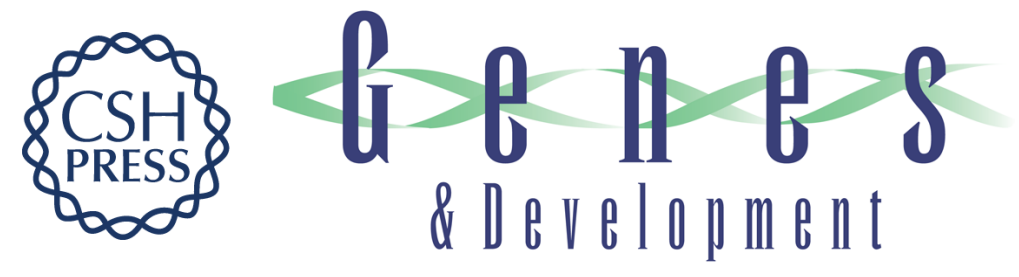

\section{Chromatin remodeling complex NURF regulates thymocyte maturation}

Joseph W. Landry, Subhadra Banerjee, Barbara Taylor, et al.

Genes Dev. 2011, 25:

Access the most recent version at doi:10.1101/gad.2007311

Supplemental

Material

References

License Freely available online through the Genes \& Development Open Access option.

Email Alerting Receive free email alerts when new articles cite this article - sign up in the box at the top Service
http://genesdev.cshlp.org/content/suppl/2011/02/02/25.3.275.DC1

This article cites 61 articles, 20 of which can be accessed free at: http://genesdev.cshlp.org/content/25/3/275.full.html\#ref-list-1 right corner of the article or click here.

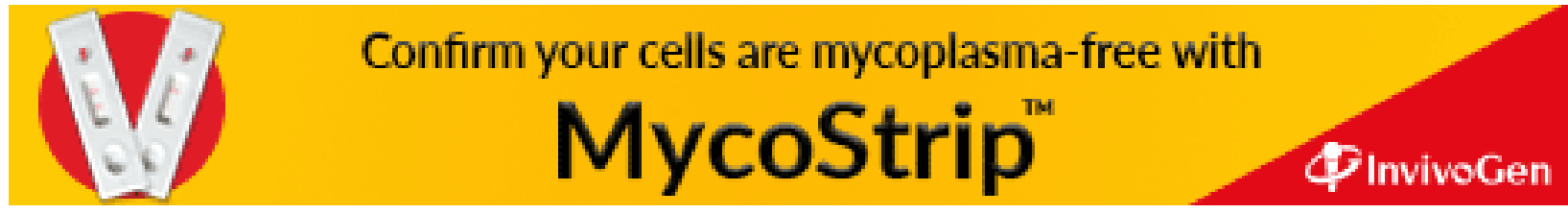

